\title{
The Role of Biofilm Formation in Antibiotic Resistance of Bacteria Isolated from Saliva of Patients with Dental Caries
}

\author{
Merriam Ghadhanfar Alwan ${ }^{1^{*}}$, Hadeel Adil Al Rubaye ${ }^{2}$, Noor Adil Abood ${ }^{3}$, \\ Hind Tahseen Ibrahem ${ }^{1}$, Hamiza Bt Hamidon ${ }^{4}$ and Asmat Ahmad ${ }^{5}$
}

${ }^{1}$ Medical Laboratory Techniques Department, Medical Technology College, Al-Farahidi University, Baghdad / Iraq.

${ }^{2}$ Pharmacy Department, Al-Rasheed College, Baghdad, Iraq. ${ }^{3}$ Medical Laboratory Techniques Department, Al-Mamoon University of College, Baghdad /Iraq. ${ }^{4}$ University Health Centre, Universiti Kebangsaan Malaysia, 43600 UKM Bangi, Selangor, Malaysia. ${ }^{5}$ School of Bioscience and Biotechnology, Faculty of Science and Technology, University Kebangsaan Malaysia, 43600 Bangi, Selangor, Malaysia.

\section{Authors' contributions}

This work was carried out in collaboration among all authors. Author MGA designed the study, wrote the protocol and wrote the first draft of the manuscript. Author AA managed the analyses of the study. Author HBH collected the samples', authors HAAR and NAA managed the literature searches, author $H T I$ performed the statistical analysis. All authors read and approved the final manuscript.

Article Information

DOI: 10.9734/ARRB/2021/v36i230341

Editor(s):

(1) Dr. David E. Martin, Martin Pharma Consulting, LLC, Shawnee and DFH Pharma Inc, Gaithersburg, Maryland

(1) Aida Meto, University of Medicine, Albania. (2) Abebe Worku Negash, Adigrat University, Ethiopia Complete Peer review History: http://www.sdiarticle4.com/review-history/66239

Original Research Article

Received 10 January 2021

Accepted 15 March 2021

Published 25 March 2021

\begin{abstract}
Objectives: This study aim to determine the bacterial diversity, biofilm forming ability and the antimicrobial resistance of bacteria isolated from saliva of patients with dental caries conditions with the using of $16 \mathrm{~S}$ rRNA gene sequencing technique for identification of the most virulent isolates.

Methods: Isolation and identification of microorganisms were done employing standard bacteriologic techniques, followed by biofilm detection using tissue culture plate method. The strong biofilm forming isolates were selected for antibiotic susceptibility test against selected antibiotics using disk diffusion technique. In order to identify the selected isolates. The genomic DNA obtained
\end{abstract}


following the extraction process were used for the amplification of the bacterial 16S rRNA gene.

Results: A total of 137 bacterial isolates were obtained and identified as belonging to 21 genera. Tissue culture plate (TCP) method were employed for screening the isolates according to its biofilm forming ability, its showed that $55(40.1 \%)$ of the total isolates were strong, $57(41.6 \%)$ were moderate and $25(18.3 \%)$ were weak biofilm producers. The antimicrobial susceptibility test showed the multi antibiotics resistance of the strong biofilm former isolates to the conventional antibiotics. Enterococcus faecalis isolates showed the highest biofilm formation and antibiotic resistance. The 16S rRNA gene for two of these isolates have been amplified using PCR and the product sequenced, analyzed and registered in the National Center for Biotechnology Information (NCBI) as UKMS1 and UKMS2 and the accession numbers KX960104.1 and KX960105.1 respectively.

Conclusion: The study has revealed that antimicrobial resistance of bacteria isolates from saliva of patients with dental caries conditions is associated with biofilm formation. Other uncommon pathogenic bacteria were also isolated in this study as a result of the use of non-selective enrichment medium for culturing. Enterococcus faecalis isolates indicated the highest biofilm formation and antibiotic resistance.

Keywords: Antimicrobial resistance; biofilm formation; oral bacteria; Enterococcus faecalis; saliva samples.

\section{INTRODUCTION}

Salivary microbial assays to determine the presence or the risk of dental diseases have been on the bases of the concept that the whole saliva is the direct source of oral biofilm bacterial organisms [1]. The buccal cavity offers two types of surfaces for bacteria colonization and these are; soft tissue surface and hard tooth enamel/exposed root surface. Thus these surfaces support the growth of different bacterial communities [2]. In view of the fact that the microbes found in saliva are collections from different surfaces of the buccal cavity, saliva flora can offer an overview of the microbial flora in the buccal cavity of an individual [2]. Recently, more scholars are focusing on the significance of saliva analysis as well as the correlation of data acquired from these analysis with the level of caries. Several studies have demonstrated strong relationship between salivary microflora and caries [3,4]. Biofilms are microbial-derived sessile communities characterized by cells that are irreversibly attached to a substratum or to each other. They are embedded in a matrix of extracellular polymeric substances (EPS) which they produced. They also exhibit an modified phenotype with reference to the rate of growth and transcription of gene [5]. Bacteria within a biofilm community communicate with each other by production of pheromones or chemotactic particles, a phenomenon known as quorum sensing [6]. The availability of key nutrients, surface adhesions, motility of bacteria, chemotaxis towards surface as well as the presence of surfactants constitute factors that affect biofilm production [6]. Microbial organisms growing in a biofilm are intrinsically more resistant to antimicrobial agents compared to planktonic cells. High antimicrobial concentrations are essential for inactivating microbial organisms growing in a biofilm, as antibiotic resistance can increase 1,000 fold [7]. The prevalence of dental biofilm forming bacteria isolates from saliva and their susceptibility pattern towards widely used antibiotics has not been fully exploited in Malaysia. We hypothesized that these biofilm forming bacteria from saliva may be responsible for increase in antibiotic resistance in patients with dental carries. The Aim of this study was to find out the prevalence of dental biofilm forming bacteria isolated from saliva samples and their susceptibility pattern towards the commonly employed antibiotics.

\section{MATERIALS AND METHODS}

\subsection{Samples Collection}

A total of 21 saliva samples were collected from patients attending Dental Clinic, Health Clinic Centre/ Seri kembangan / Selangor/ Malaysia and Dental Clinic, UKM/ Bangi /Malaysia. Each patient were given printed paper to explain the aim of this study and consent was obtained from them. Twenty one patients were selected for inclusion in the study. The patients were chosen randomly males and females, who did not used antibiotics for the last 3 months and all patients have various dental and periodontal problems. The samples were unstimulated saliva and collected by special dentist. Saliva samples 
were collected in sterilized tubes which were then transported to the Lab within $2 \mathrm{~h}$ [8].

\subsection{Isolation and Identification}

Isolation and identification of aerobic, anaerobic and facultative organisms were done employing standard bacteriologic techniques. Ten-fold serial dilutions for the samples were prepared using peptone water. Following dilutions, the diluted samples were spread $(0.1 \mathrm{ml})$ on Brain Heart agar (BHIA) (Oxoid) plates. Then the cultured plates were incubated aerobically and anaerobically for $1-5$ days at $37{ }^{\circ} \mathrm{C}$. All the microbial cultural features of isolates on the selective media such as elevation, size, shape, margin, and pigmentation of colony were recorded [9]. By using Bergey's Manual of Systematic Bacteriology, the biochemical properties of the isolates were tested and recorded [10]. The properties determined include Oxidase test, Catalase test, TSI test, acid production from carbohydrates, Simmon citrate test, and Analytical Profile Index (API) kits were used for further identification of the isolates.

\subsection{Biofilm Formation}

Biofilm detection was assayed using tissue culture plate method, it's considered as a quantitative determination technique of biofilm using 96 well microtitre plate. This technique used to detect the ability of the isolates to form biofilm on abiotic surfaces. After overnight incubation in brain heart infusion broth (BHIB), containing $1 \%$ glucose at $37^{\circ} \mathrm{C}, 200 \mu \mathrm{L}$ of the suspension was diluted to $1: 40$ and subsequently introduced in triplicates into sterile 96-well polystyrene microtiter plates (Sigma Aldrich, USA). Sterile BHI broth was used as a control for the screening, while Staphylococcus epidermidis ATCC 12228 (non biofilm former) was used as a negative control. Staphylococcus epidermidis ATCC 35984 also was used as a positive control. Following incubation at $37^{\circ} \mathrm{C}$ for $24 \mathrm{~h}$ period, the wells were washed with $0.2 \mathrm{~mL}$ phosphate buffered saline (PBS). The plates were dried in an inverted position for $1 \mathrm{~h}$ at room temperature. The wells were subsequently stained with $1 \%$ crystal violet (CV) for $15 \mathrm{~min}$ at room temperature. Surplus $\mathrm{CV}$ stain were washed off using PBS, after that $\mathrm{CV}$ was extracted from adhering bacterial cells using 200 $\mu \mathrm{L}$ of $80: 20(\mathrm{v} / \mathrm{v})$ ethyl alcohol/acetone. The OD of the wells were read at $570 \mathrm{~nm}\left(\mathrm{OD}_{570}\right)$ using microplate ELISA reader (BioRad, USA) [11]. All tests were performed in triplicate and the average was used. The bacterial isolates were then categories as; no biofilm producer, weak biofilm producer, moderate biofilm producer and strong biofilm producers [11]. For this, it was necessary to establish the cut-off value (ODc). The ODc was defined as three standard deviations (SD) above the mean OD of the negative control (uncultured $\mathrm{BHI}$ broth): $\mathrm{ODc}=$ average $\mathrm{OD}$ of negative control $+(3 \times \mathrm{SD}$ of negative control). Based upon the OD values: $\mathrm{OD} \leq \mathrm{ODc}=$ non-biofilm former; ODc $<\mathrm{OD} \leq 2 \times$ ODc = weak biofilm former; $2 \times O D c<O D \leq 4 \times O D c=$ moderate biofilm former; 4 $\times O D c<O D=$ strong biofilm former.

\subsection{Antibiotic Susceptibility Test}

The strong biofilm forming isolates $(n=55)$ were selected for antibiotic susceptibility test against selected antibiotics using disk diffusion (kirby Bauer's) technique. This method was done according to Clinical and Laboratory Standards Institute (CLSI) guidelines [12]. This test was carried out on Mueller Hinton agar (Oxoid, UK), using the following antibiotic discs (Oxoid, UK): amoxycillin AML $(10 \mu \mathrm{g})$, erythromycin E $(30 \mu \mathrm{g})$, ampicillin AMP $(10 \mu \mathrm{g})$, cephalothin KF $(30 \mu \mathrm{g})$, chloramphenicol C $(30 \mu \mathrm{g})$, tetracycline $(30 \mu \mathrm{g})$, ciprofloxacin CIP $(10 \mu \mathrm{g})$, nalidixic acid NA $(30 \mu \mathrm{g})$ , vancomycin VA $(30 \mu \mathrm{g})$, gentamicin CN $(10 \mu \mathrm{g})$, novobiocin NV $(30 \mu \mathrm{g})$, carbenicillin CAR $(100 \mu \mathrm{g})$, kanamycin $\mathrm{K}(30 \mu \mathrm{g})$, oxacillin $\mathrm{OX}(5 \mu \mathrm{g})$, penicillin

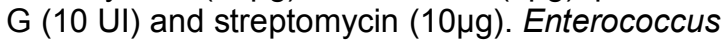
faecalis ATCC 33186 was used as control strains.

\subsection{Molecular Identification and Phylogenetic Analysis}

Genomic DNA was extracted using wizard ${ }^{\circledR}$ Genomic DNA purification kit (Promega Corporation, USA), following manufacturer's instruction. In order to identify the selected isolates. The genomic DNA obtained following the extraction process were used for the amplification of the bacterial 16S rRNA gene using the forward primers (FP 5'AGAGTTTGATCCTGGCTCAG-3) and reverse primer (RP 5' ACGGTTACCTTGTTACGACTT3). GoTaq® Flexi DNA Polymerase (Promega Corporation, USA) was used to performed PCR reaction. A prime thermal cyclers (Techne, UK) was used to carry out the amplification at an initial denaturation step with $95^{\circ} \mathrm{C}$ temperature for $2 \mathrm{~min}, 35$ cycles of $95^{\circ} \mathrm{C}$ for $1 \mathrm{~min}$, at $50^{\circ} \mathrm{C}$ for $1 \mathrm{~min}$, at $72^{\circ} \mathrm{C}$ for $1 \mathrm{~min}$, and a final extension step at $72^{\circ} \mathrm{C}$ for $5 \mathrm{~min}$. The amplified PCR 
products were separated by agarose gel electrophoresis technique on $1.5 \%$ (w/v) agarose gel in 1X TAE buffer $(40 \mathrm{mM}$ Trisacetate, $1 \mathrm{mM}$ EDTA, pH 8.0) at $80 \mathrm{~V}$ for $45 \mathrm{~min}$. The gel was pre-stained with Floro Safe DNA Stain (BIO-5170-1ml)/1st BASE Pte Ltd, while Exact Mark 1kb DNA Ladder (BIO-5140) /1st BASE Pte Ltd was used as a marker for the DNA size. Lastly, the gels were examined and captured by UV trans-illuminator Gel Documentation system (syngene, UK).

\subsection{Statistical Analysis}

The Excel data analysis package was used to calculate mean, standard deviation of the mean for the tissue culture plate method data. All the results were calculated from the mean of three replicate samples for each data point.

\section{RESULTS AND DISCUSSION}

\subsection{Bacterial Identification}

Majority of earlier studies on saliva microflora used semi-selective media for the isolation of oral bacteria $[3,13,14]$. In order to increase the number of bacterial species collected and response to nutritional differences in microbial growth, this study employed non-selective enrichment media $(\mathrm{BHI})$ for the isolation of the bacteria from saliva samples. A total of 137 bacterial isolates were obtained and identified from these saliva samples. The Isolates were encoded from S1 until S137. Following the subjection of the isolates to gram staining, $65 \%$ of total isolates were found to be Gram positive while $35 \%$ of total isolates were Gram negative. Anaerobic and aerobic culturing revealed that $72 \%$ of total isolates were facultative anaerobic whereas others were obligate anaerobes (18\%) and aerobic (10\%) microorganisms. According to the cell morphology, $48 \%$ of total isolates were cocci while $52 \%$ were rod. All the phenotypic characteristics were shown in Fig. 1.

In total, 137 bacterial isolates comprising 21 genera were identified, the most abundant of which was Enterococcus sp. (14.6\%). This is an interesting finding, since Enterococcus sp. is not generally considered to be a common bacteria from the saliva, even though it has been previously reported [8] to be present in about 5\% as a normal flora. In this study, following Enterococcus sp., the second-most prevalent microbial organism identified was Streptococcus sp. (13.1\%). These findings corroborate with the findings reported in an earlier study where
Streptococcus sp. was reported to play an important role in the pathogenesis of caries by modifying the dental plaque environment to favor the succession of aciduric species [15]. Staphylococcus sp. was found to be the third most prevalent bacterial genus identified, next to Enterococcus sp. and Streptococcus sp. Staphylococci are common residents of the nasal flora [16] and [17] and thus they may consistently be found in the buccal cavity. The next most prevalent bacterial genus from the saliva was Bacillus species, which was found to be present at the rate of $6.5 \%$. These species are generally considered as transient inhabitants of the healthy human buccal cavity (2). However, in an animal study, it has been reported that Bacillus species elaborate a potent exogenous factor(s) capable of activating the kallikrein-kinin metabolic pathway in intact oral mucosa, resulting to exudation of plasma and tissue dysfunction [18]. Other bacterial genera also identified these are Pseudomonas sp., Enterobacter sp., Escherichia coli, Proteus sp., Klebsiella sp., Clostridium sp., Actinomyces sp., Micrococcs sp., Lactobacillus sp., Bacteroides sp., Fusobacterium sp., Provotella sp., Salmonella sp., Aerococcus sp., Peptostreptococcus sp., Shigella sp., and Eubacterium sp. This study equally appears to be the first to report the isolation of Salmonella and Shigella species from saliva sample of humans. Salmonella can easily exist in dry dog kibble, and can also exist in raw meat that it's given to feed pets animals like dogs, also [19] mentioned the presence of Salmonella serotypes in pet chews. In this study our samples collected from patients already have dental and periodontal caries, this perhaps shows that there are abundance of Enterococcus sp. and other oral pathogens in saliva that are yet to be isolated. Table 1 shows all the 21 genera of the identified bacteria from the saliva samples.

\subsection{Biofilm Formation}

Among the 137 isolates, TCP demonstrated that $55(40.1 \%)$ were strong biofilm formers, 57 $(41.6 \%)$ were moderate biofilm formers and 25 $(18.3 \%)$ were weak biofilm formers. The results showed that $80 \%, 55.6 \%, 62.5 \%, 55.6 \%, 54.5 \%$, $60 \%$ and $71.4 \%$ of Enterococcus sp., Streptococcus sp., Staphylococcus sp., Bacillus sp., E. coli, Pseudomonas sp. and Proteus sp. respectively are strong biofilm producers Fig. 3, while biofilm forming ability varied between moderate and weak in the other genera isolated in this study. This result partially agreed with the 
findings of [20] who reported that majority of organisms associated with biofilm production were S. epidermidis (37.1\%) followed by E. coli $(27.1 \%)$, K. pneumoniae $(15.7 \%)$, S. aureus $(11.4 \%)$, E. faecalis $(4.2 \%)$ and $P$. aeruginosa $(4.2 \%)$. In this study, Enterococcus sp. showed the highest ability to form biofilm. The adherence and production of a biofilm by $E$. faecalis on different biomaterials have been demonstrated, and the capacity of enterococci to bind to various medical devices has been attributed to its ability to produce biofilms [21].

Cutoff value is needed to categorize the isolates to (Weak, Moderate, Strong) biofilm formers (Fig. 4 ). The cutoff value of the readings was 0.346 , according to this value the biofilm formation equations will be: $\mathrm{OD}_{570} \leq 0.346=$ non-biofilm producers; $0.346<\mathrm{OD}_{570} \leq 0.693=$ weak biofilm producers; $0.693<\mathrm{OD}_{570} \leq 1.387=$ moderate biofilm producers; $1.387<\mathrm{OD}_{570}=$ strong biofilm producers. Fig. $5(A, B$ and $C)$ shows the quantitative results of tissue culture plate method which reveals that all the isolates has the ability to form biofilm but in varying degrees.

\subsubsection{Antibiotic susceptibility test}

Strong biofilm producing isolates were subjected to screening for antimicrobial susceptibility test. These isolates were found to have increased resistance to conventional antibiotics such as penicillin $(100 \%)$, ampicillin $(78 \%)$, nalidixic acid (87\%), cephalothin (87\%), chloramphenicol (76\%), oxacillin (75\%), novobiocin (80\%), streptomycin (75\%), erythromycin (67\%), vancomycin (65\%), amoxicillin (60\%), carbenicillin (60\%) ciprofloxacin (55\%) and tetracycline (51\%). While lower degrees of resistance to kanamycin $(42 \%)$ and gentamicin $(44 \%)$. These findings corroborated with the report of Wood $\mathrm{R}$ who reviewed the antibiotic

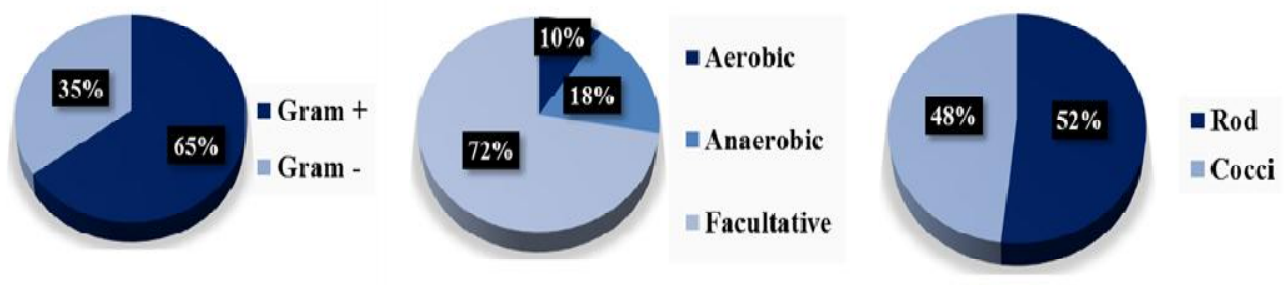

Fig. 1. The microbiological phenotypic characteristics prevalence of the isolates

Table 1. The numbers and percentages of the bacterial isolates according to genera

\begin{tabular}{lll}
\hline Genus & No. of isolates & Percentage (\%) \\
\hline Enterococcus sp. & 20 & 14.6 \\
Streptococcus sp. & 18 & 13.1 \\
Staphylococcus sp. & 16 & 11.7 \\
Bacillus sp. & 9 & 6.6 \\
Actinomyces sp. & 3 & 2.2 \\
E. coli & 11 & 8.0 \\
Salmonella sp. & 4 & 2.9 \\
Shigella sp. & 2 & 1.5 \\
Pseudomonas sp. & 5 & 3.6 \\
Klebsiella sp. & 4 & 2.9 \\
Clostridium sp. & 8 & 5.8 \\
Micrococcs sp. & 4 & 2.9 \\
Enterobacter sp. & 6 & 4.4 \\
Proteus sp. & 7 & 5.1 \\
Peptostreptococcus sp. & 4 & 2.9 \\
Lactobacillus sp. & 3 & 2.2 \\
Fusobacterium sp. & 3 & 2.2 \\
Eubacterium sp. & 2 & 1.5 \\
Provotella sp. & 2 & 1.5 \\
Bacteroides sp. & 4 & 2.9 \\
Aerococcus sp. & 2 & 1.5 \\
\hline
\end{tabular}


sensitivity pattern of pathogenic microorganisms over a span of 20 yrs. (1966 1986) [22]. The said author found that there was a continuous decline in the sensitivities of bacteria isolates to most of the antibiotics used in dental practice. Slowly and persistently, resistant strains of all types of microbial organisms encountered in dental practice are emerging. These resistance might be attributed to biofilm production, in view of the fact that almost half of biofilm producers are simultaneously resistant to at least three different groups of antibiotics [23], and the physiological characteristics of the microbial organisms that produce biofilm allow intrinsic resistance to antimicrobial agents. The resistance mechanisms are usually based on the delayed penetration of the antimicrobial agent, changes in the microbial growth rate or other physiological alterations related to the development of biofilm [5]. The antibiotics resistance ability of the strong biofilm producing isolates are depicted in Fig. 5.

\subsubsection{Molecular characterization and phylogenetic analysis based on $16 \mathrm{~s}$ rRNA gene sequence}

The 16S rRNA gene sequences of two most strong biofilm former and antibiotics resistant isolates were selected for analysis. These isolates were further identified as Enterococcus faecalis. The purified 16S rRNA gene sequence were successfully recovered form UKMS1 and UKMS2 Fig. 6 (A). The PCR products were approximately $1500 \mathrm{~kb}$ in size corresponding to these group of bacteria. The comparison of DNA sequences with sequences in GenBank was also compared with number series and maximum identification percent. All sequences gave similarity of about $99 \%$. According to $16 \mathrm{~S}$ gene sequences in GenBank, the two strains cluster with Enterococcus faecalis. The phylogenetic tree Fig. 6 (B) was constructed to show the relationship and comparison of our bacteria sequences data and previously published data from NCBI (GenBank). UKMS1 and UKMS2 were clustered together (bootstrap $100 \%$ ) and these isolates clustered with Enterococcus faecalis (bootstrap 99\%). The $16 \mathrm{~S}$ rRNA gene for these isolates have been, registered in the National Center for Biotechnology Information (NCBI) as UKMS1 and UKMS2 with the accession numbers KX960104.1 and KX960105.1 respectively. The evolutionary history was inferred using the Neighbour-Joining method. Confidence values were assessed from 1,000 bootstrap replicates of the original sequence data and are shown next to the branches. The scale indicates the evolutionary distances computed using the $p$ distance method and are in the units of the number of amino acid differences per site. The analysis involved 7 amino acid sequences. Evolutionary analyses were conducted using MEGA6.

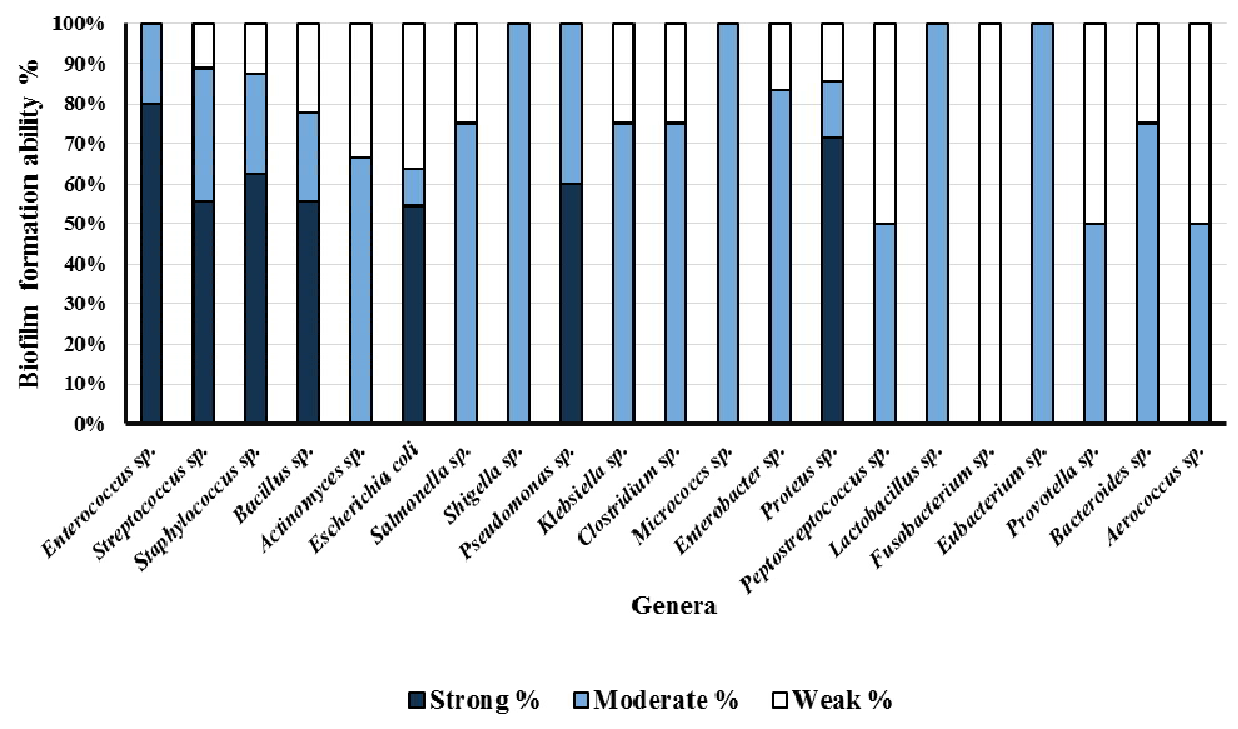

Fig. 2. Biofilm formation ability of the isolates isolated from saliva 
A

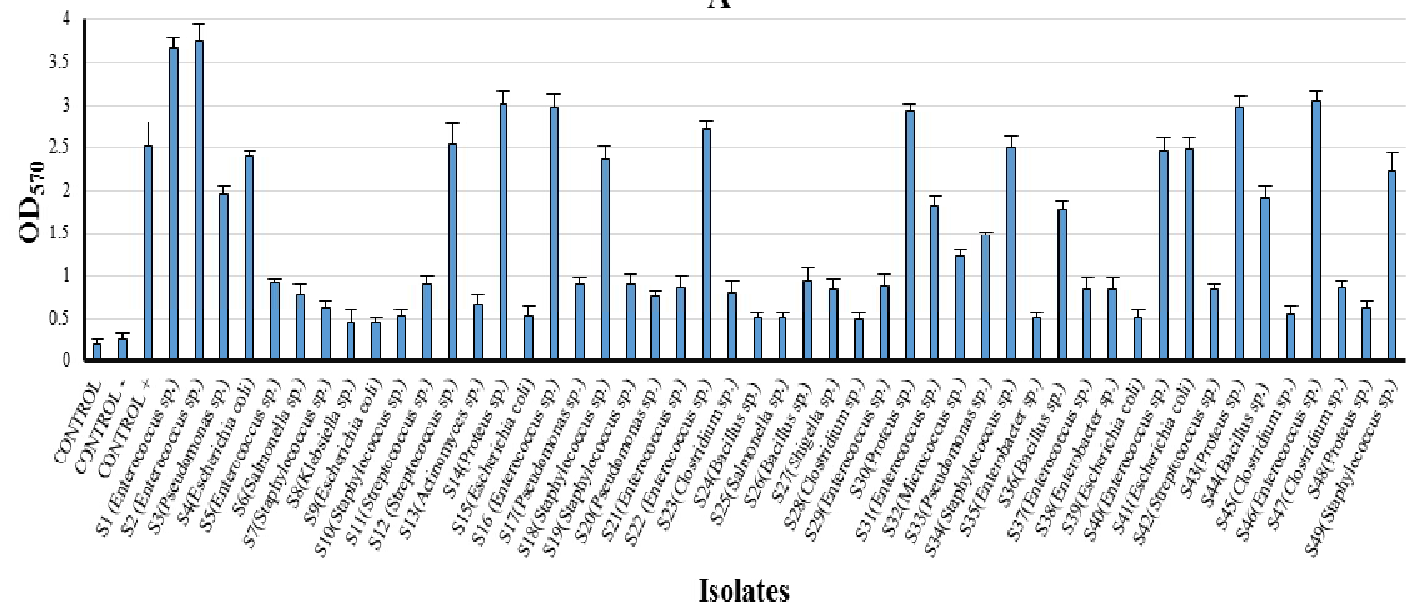

B
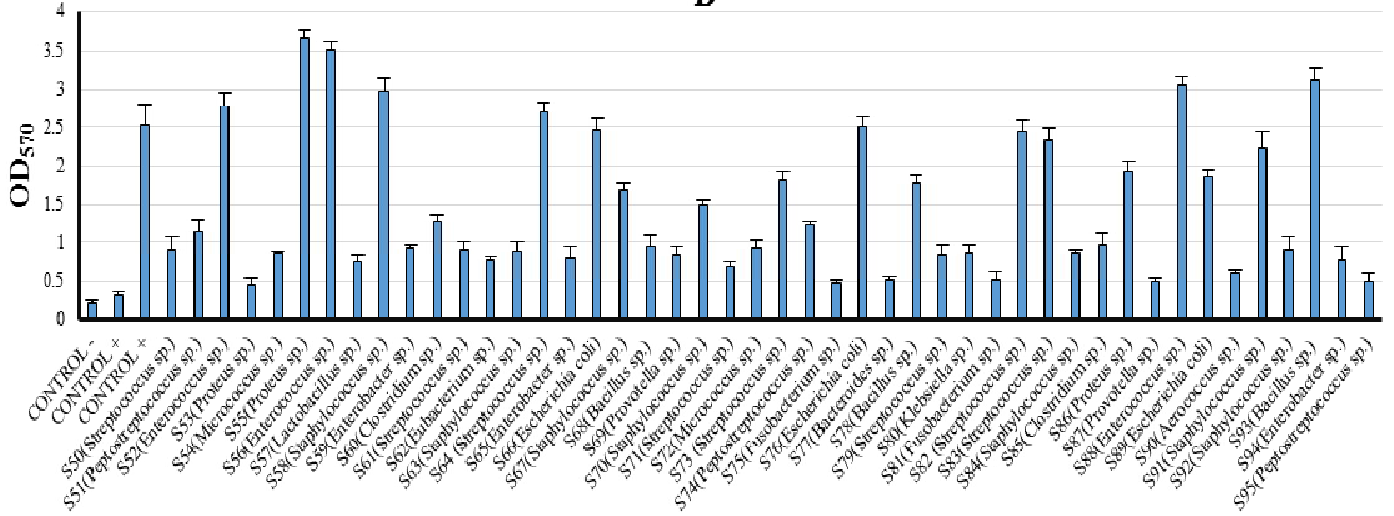

Isolates

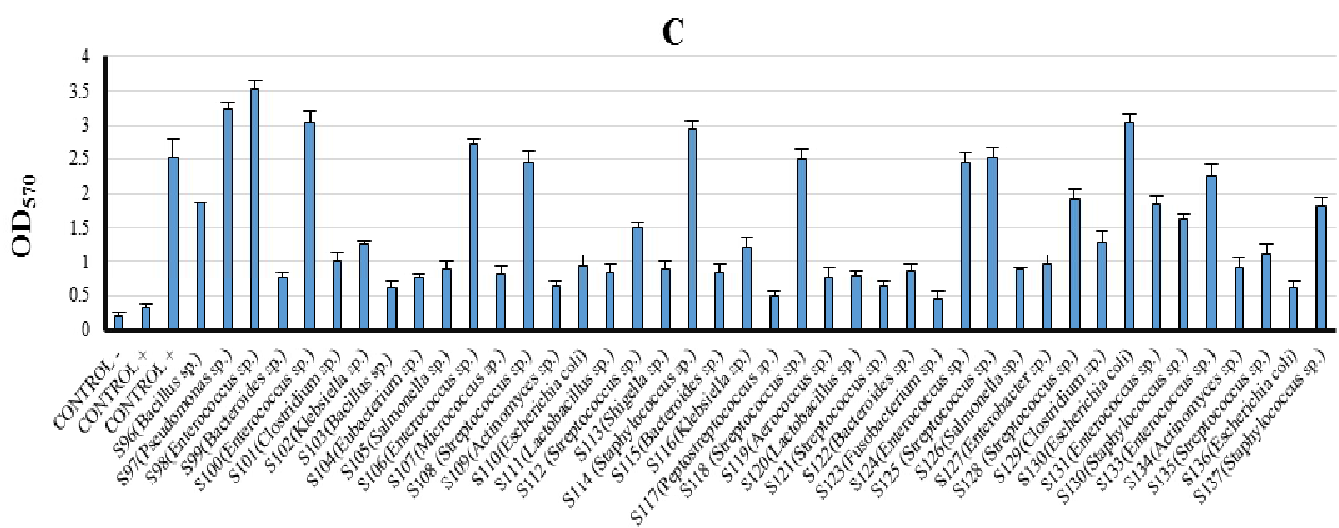

Isolates

Fig. 3. Screening biofilm forming ability of the isolates using tissue culture plate method; (A) Isolates from S1 to S49 (B) Isolates from S50 to S95 (C) Isolates from S96 to S137 


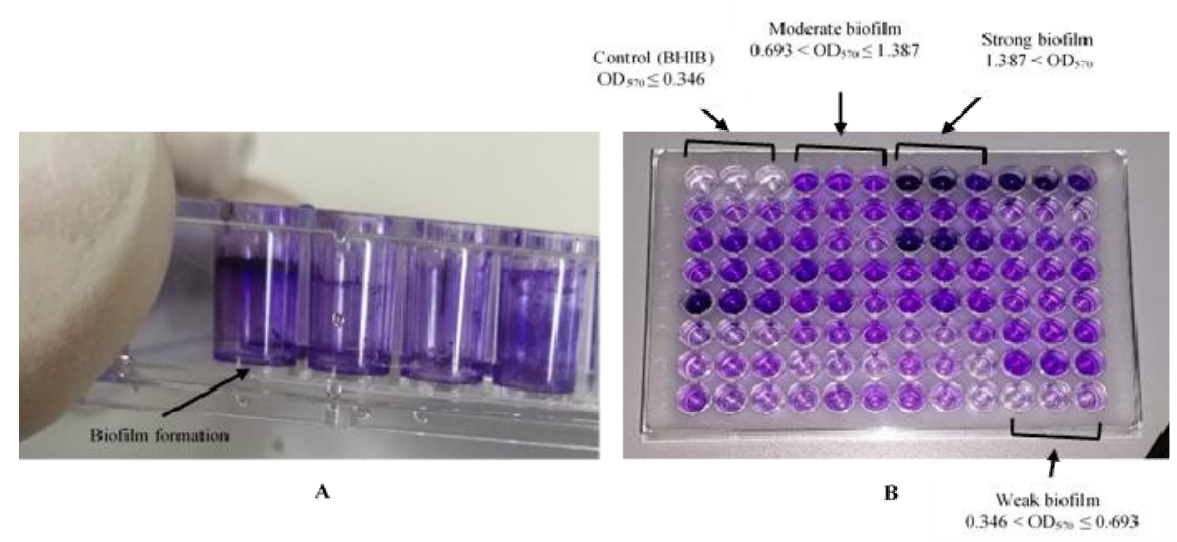

Fig. 4. Quantitative detection of biofilm Formation of the isolates; (A) Strong biofilm formation by $\mathrm{S} 1$ (Enterococcus sp); (B) Strong, moderate, weak biofilm formers differentiated by crystal violet staining in 96 well microtiter plates

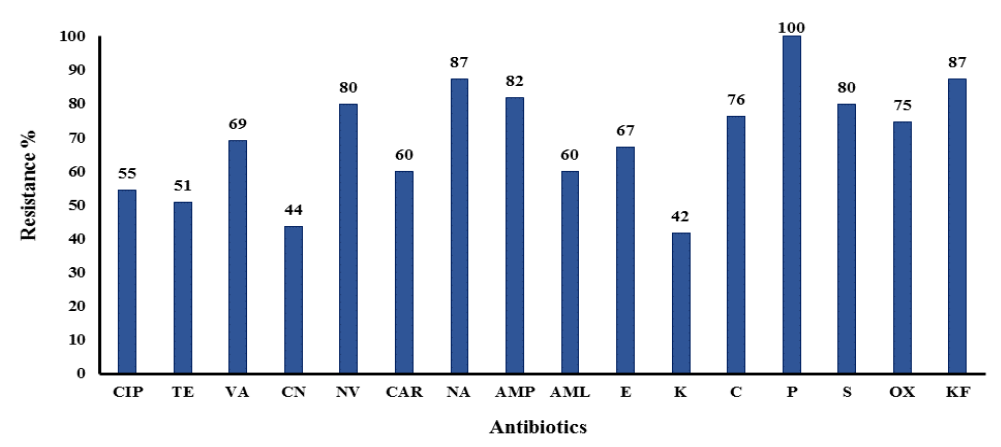

Fig. 5. Levels (\%) of antibiotic resistance demonstrated by Strong biofilm producing isolates
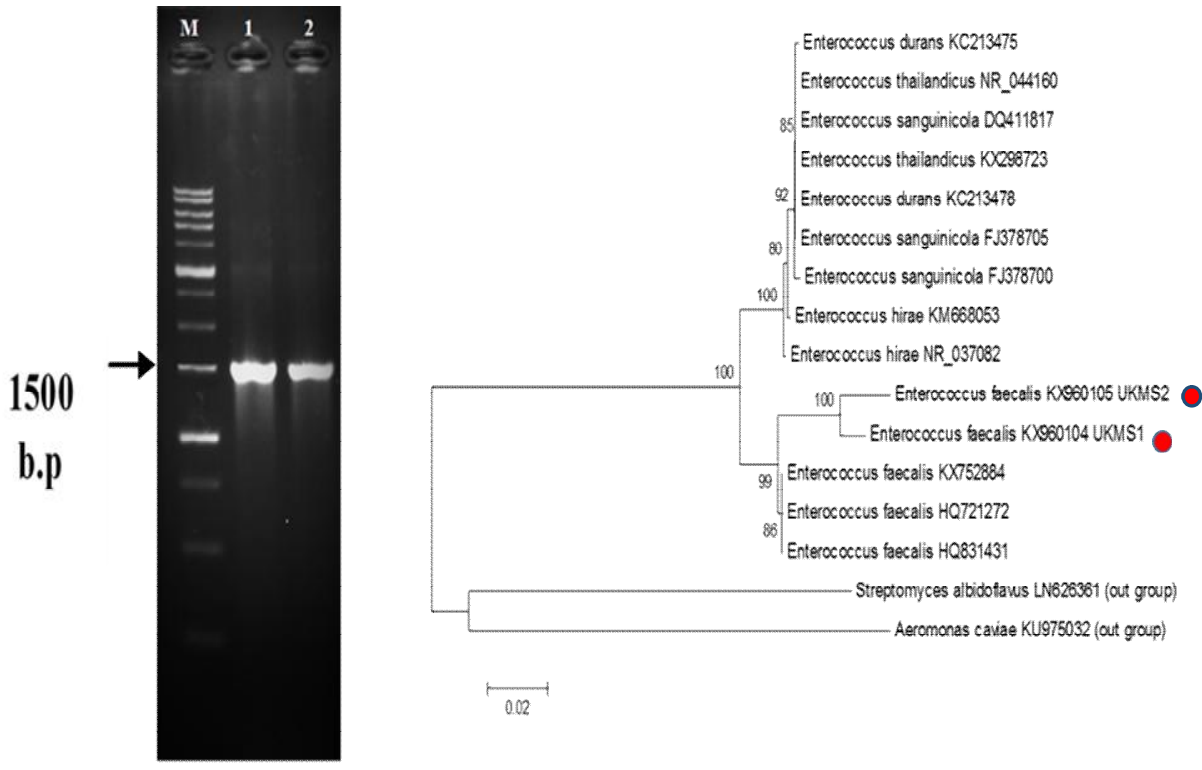

Fig. 6. (A) Agarose gel electrophoresis of purified 16S rDNA for UKMS1 and UKMS2 (B) Phylogenetic tree displaying evolutionary relationships 


\section{CONCLUSION}

The prevalence of saliva microflora was determined in this study and Enterococcus species were found to be the most abundant species in the saliva. The study has revealed that antimicrobial resistance of bacteria isolates from saliva of patients with dental caries conditions is associated with biofilm formation. Other uncommon pathogenic bacteria were also isolated in this study as a result of the use of non-selective enrichment medium for culturing. In view of the importance of antimicrobial resistance of bacterial isolates from saliva, the findings of this study is impressive. However further studies are required to further identify possible means to over the resistance of bacterial flora of saliva to antimicrobial agents.

\section{DISCLAIMER}

The products used for this research are commonly and predominantly use products in our area of research and country. There is absolutely no conflict of interest between the authors and producers of the products because we do not intend to use these products as an avenue for any litigation but for the advancement of knowledge. Also, the research was not funded by the producing company rather it was funded by personal efforts of the authors.

\section{CONSENT}

Each patient was given printed paper to explain the aim of this study and consent was obtained from them. Twenty one patients were selected for inclusion in the study

\section{ACKNOWLEDGEMENT}

The authors are grateful to the School of Biosciences and Biotechnology and the Faculty of Science and Technology, Universiti Kebangsaan Malaysia for providing financial and moral support by grants 04-01-02-SF1244 from Ministry of Science, Technology and Innovation (MOSTI) of Malaysia. The authors also appreciate the stuff of the Dental Clinic, Health Clinic Centre, Seri kembangan, Selangor and Dental Clinic, UKM/ Bangi in Malaysia.

\section{COMPETING INTERESTS}

Authors have declared that no competing interests exist.

\section{REFERENCES}

1. Slots J, Slots H. Bacterial and viral pathogens in saliva: disease relationship and infectious risk. Periodontology 2000. 2011;55(1):48-69.

2. Marcotte $\mathrm{H}$, Lavoie MC. Oral microbial ecology and the role of salivary immunoglobulin A. Microbiology and molecular biology reviews. 1998;62(1):71109.

3. Gabris K, Nagy G, Madlena M, Dénes Z, Marton S, Keszthelyi G, et al. Associations between microbiological and salivary caries activity tests and caries experience in Hungarian adolescents. Caries research. 1999;33(3):191-5.

4. Llena-Puy MC, Montañana-Llorens C, Forner-Navarro L. Cariogenic oral flora and its relation to dental caries. ASDC journal of dentistry for children. 2000;67(1):42-6, 9.

5. Donlan RM, Costerton JW. Biofilms: survival mechanisms of clinically relevant microorganisms. Clinical microbiology reviews. 2002;15(2):167-93.

6. Danhorn T, Fuqua C. Biofilm formation by plant-associated bacteria. Annu Rev Microbiol. 2007;61:401 22.

7. Stewart PS, Costerton JW. Antibiotic resistance of bacteria in biofilms. The lancet. 2001;358(9276):135-8.

8. Özdabak N, Karaoğlanoğlu $S$, Akgül N, Seven N. Identification of aerobic bacterial flora in saliva of subjects who apply to the faculty of dentistry in Atatürk University by using microbial identification system. Atatürk Üniversitesi Diş Hekimliği Fakültesi Dergisi. 2012;2012(1).

9. Prescott L, Harley J, Klein D. Isolation of pure cultures. Microbiology, 5th Edition, The McGraw-Hill Companies, New York. 2002:106-10.

10. Vos P, Garrity G, Jones D, Krieg NR, Ludwig W, Rainey FA, et al. Bergey's manual of systematic bacteriology. The Firmicutes: Springer Science \& Business Media. 2011;3.

11. Elhadidy M, Elsayyad A. Uncommitted role of enterococcal surface protein, Esp, and origin of isolates on biofilm production by Enterococcus faecalis isolated from bovine mastitis. Journal of Microbiology, Immunology and Infection. 2013;46(2):804.

12. Bauer A, Kirby W, Sherris JC, Turck M. Antibiotic susceptibility testing by a 
standardized single disk method. American journal of clinical pathology. 1966;45(4):493.

13. Beighton D, Manji F, Baelum V, Fejerskov $\mathrm{O}$, Johnson $\mathrm{N}$, Wilton J. Associations between salivary levels of Streptococcus mutans, Streptococcus sobrinus, lactobacilli, and caries experience in Kenyan adolescents. Journal of dental research. 1989;68(8):1242-6.

14. Gudkina J, Brinkmane A. Caries experience in relation to oral hygiene, salivary cariogenic microflora, buffer capacity and secretion rate in 6-year olds and 12 year olds in Riga. Stomatologija. 2008;10(2):76-80.

15. Brailsford $\mathrm{S}$, Byrne $\mathrm{R}$, Adams $\mathrm{S}$, Zoitopoulos L, Allison C, Beighton D. Investigation of the aciduric microflora of plaque. Caries Research. 1999;33(4):290.

16. Kluytmans J, Van Belkum A, Verbrugh $\mathrm{H}$. Nasal carriage of Staphylococcus aureus: epidemiology, underlying mechanisms, and associated risks. Clinical microbiology reviews. 1997;10(3):505-20.

17. Güçlü E, Yavuz T, Tokmak A, Behcet M, Karali E, Öztürk Ö, et al. Nasal carriage of pathogenic bacteria in medical students: effects of clinic exposure on prevalence and antibiotic susceptibility. European archives of oto-rhino-laryngology. 2007;264(1):85-8.
18. Rubinstein I, Pedersen GW. Bacillus species are present in chewing tobacco sold in the United States and evoke plasma exudation from the oral mucosa. Clinical and diagnostic laboratory immunology. 2002;9(5):1057-60.

19. Wong $\mathrm{T}$, Thom $\mathrm{K}$, Nicol $\mathrm{C}$, Heffernan $\mathrm{H}$, MacDiarmid S. Salmonella serotypes isolated from pet chews in New Zealand. Journal of applied microbiology. 2007;103(4):803-10.

20. Hassan A, Usman J, Kaleem F, Omair M, Khalid $A$, lqbal $M$. Evaluation of different detection methods of biofilm formation in the clinical isolates. The Brazilian Journal of Infectious Diseases. 2011;15(4):305-11.

21. Joyanes $P$, Pascual $A$, Martinez-Martinez L, Hevia A, Perea E. In vitro adherence of Enterococcus faecalis and Enterococcus faecium to urinary catheters. European Journal of Clinical Microbiology and Infectious Diseases. 2000;19(2):124-7.

22. Woods R. Twenty years of antibiotic sensitivity testing of dental infections. Part 2. A review, 1966-1986. Australian dental journal. 1988;33(6):505-10.

23. Alves MJ, Barreira JC, Carvalho I, Trinta L, Perreira L, Ferreira IC, et al. Propensity for biofilm formation by clinical isolates from urinary tract infections: developing a multifactorial predictive model to improve antibiotherapy. Journal of medical microbiology. 2014;63(3):471-7.

(c) 2021 Alwan et al.; This is an Open Access article distributed under the terms of the Creative Commons Attribution License (http://creativecommons.org/licenses/by/4.0), which permits unrestricted use, distribution, and reproduction in any medium, provided the original work is properly cited.

Peer-review history:

The peer review history for this paper can be accessed here: http://www.sdiarticle4.com/review-history/66239 